\title{
Clinical Evaluation of Topical Metronidazole and Chlorhexidine Gel following Scaling and Root Planing in Patients with Chronic Periodontitis
}

\author{
Pujan Acharya, ${ }^{1}$ Manoj Kumar, ${ }^{2}$ CS Saimbi ${ }^{3}$ \\ ${ }^{1}$ Department of Periodontology and Oral Implantology, College of Dental Surgery, BPKIHS, Dharan, Nepal, ${ }^{2}$ B.R.D. \\ Medical College, Gorakhpur, Uttar Pradesh, India, ${ }^{3}$ Department of Periodontology and Oral Implantology, Universal \\ College of Medical Sciences, Bhairahawa, Nepal.
}

\begin{abstract}
Background: Chronic periodontitis is the most prevalent form of periodontitis with a multifactorial etiology, dental plaque being the primary etiologic agent. The removal of such etiologic factor through scaling and root planing builds the foundation of treatment. In addition, the use of an antimicrobial adjunct augments elimination of microbes leading to subsequent control of the disease. Chlorhexidine and Metronidazole have been found to be active against several periodontopathogens. In this study, the use of these antimicrobial gels has been made. To evaluate and compare the clinical efficacy of subgingival application of $1 \%$ Metronidazole, $1 \%$ Chlorhexidine and Combination gel when used as an adjunct to non-surgical therapy. Methods: A total of 120 patients, age group 30-60 years with chronic generalized periodontitis were included in the randomized, controlled, double blinded study. The patients were randomly divided into four groups and treated with scaling and root planing along with antimicrobial adjunct. The antimicrobials used were Chlorhexidine, Metronidazole, Combination of Chlorhexidine and Metronidazole, and Placebo. Clinical parameters (plaque index, gingival index, probing pocket depth and clinical attachment level) were recorded at baseline, 1 month and 3 months. Results: In all the groups, there was a statistically significant reduction in all the clinical parameters at different time intervals. Inter-group comparison with respect to clinical changes showed that Combination gel was the best. Conclusions: Long term, controlled randomized trials with more samples are suggested to further validate the efficacy of these antimicrobial drugs.
\end{abstract}

Keywords: chlorhexidine; chronic periodontitis; metronidazole; scaling and root planing.

\section{INTRODUCTION}

Chronic periodontitis, characterized by chronic inflammatory changes in the marginal gingiva, presence of periodontal pockets, attachment and bone loss, subsequently can lead to tooth mortality. Dental biofilm has been considered to play a major role in initiation and progression of periodontal diseases along with microbial, host, environmental and genetic factors. Elimination of pathogenic bacteria present in inflamed pocket can arrest disease progression which is achieved by mechanical scaling and root planing (SRP), that is considered gold standard for non-surgical management of chronic periodontitis. ${ }^{1}$ However, the tissue invasive nature of certain pathogens as well as the restricted periodontal instrumentation to inaccessible areas like furcation, dentinal tubules etc may fail to eradicate the pathogens successfully. Thus, to overcome these limitations, researchers have suggested the use of systemic or local antimicrobial therapy. ${ }^{2}$ Though both the modes of drug delivery have their own significance, local delivery offer several advantages compared to systemic therapy. Goodson et al (1979) first proposed the concept of controlled delivery in the treatment of periodontitis. ${ }^{3}$ This system of delivery can provide higher concentration of medication to the targeted site for longer duration. Moreover, it can limit the adverse effects of systemic administration and prevent bacterial resistance.

Among various antimicrobial agents, chlorhexidine (CHX) is one of the most effective agents which is considered gold standard. ${ }^{4}$ It has been found to be effective against subgingival bacteria when delivered through a sustained release device. The first sustained release dosage form of CHX diacetate for topical use was developed by Friedman and Golomb in $1982 .{ }^{5}$ Its affinity for hydroxyapatite and

Correspondence: Dr. Pujan Acharya, Department of Oral Medicine and Radiology, College of Dental Surgery, BPKIHS, Dharan, Nepal. Email: poojan_drn@yahoo.com. Phone: +977-9852021910. Orcid ID: https://orcid.org/0000 -0002-7216-8430. DOI: 10.3126/jcmsn.v15i1.19197. Article Received: 2018-02-15. Article accepted: 2018-09-06. 
acidic salivary glycoprotein is accountable for its remarkable retention in the oral cavity which in turn has proved to be advantageous in the treatment of periodontal diseases. ${ }^{6}$ Another drug is metronidazole (MTZ), the anaerobic activity of which was a serendipitous discovery. It was introduced in the 1960s to a woman for vaginal trichomoniasis $^{7}$ and she was also known to have acute ulcerative gingivitis which concurrently responded for the treatment of trichomoniasis. ${ }^{8}$ It has a bactericidal effect against anaerobic organisms and some facultative anaerobic bacteria are also sensitive to its concentration after its local application. ${ }^{9}$ These organisms are predominant in subgingival flora in chronic periodontitis. Studies have demonstrated that subgingival application of MTZ as monotherapy ${ }^{10}$ or along with non-surgical periodontal therapy (NSPT) $)^{11-12}$ has yielded good results. Its effect on subgingival plaque and certain clinical parameters in periodontal disease has since been studied in both animals and humans. In the recent years, the development of a slow release formulation has resulted in the production of MTZ $25 \%$ dental gel which has been shown to have bactericidal effect against some of the potential periodontopathic bacteria. ${ }^{13}$ Therefore, the aim of this study was to compare the clinical efficacy of these antimicrobial gels minimizing the risk of side effects following systemic administration.

\section{METHODS}

\section{Ethics}

The ethical clearance for the research protocol was obtained from the Institutional Ethical, Research and Academic Committee, Universal College of Medical Sciences (UCMS), Tribhuvan University, Nepal. Interested individuals were verbally briefed about nature and details of the study. Informed consent was received from all the participants.

\section{Study Design and Setting}

The study was conducted as a placebo controlled, double blinded, randomized clinical trial. Participants visiting the department of Periodontology and Oral Implantology, UCMS Bhairahawa, diagnosed with chronic periodontitis were randomized into control and test groups. All enrolled individuals received non-surgical periodontal therapy (NSPT) at baseline visit followed by topical application of Chlorhexidine, Metronidazole, Combination and Placebo gel followed by recalls at 1 month and 3 months interval.

\section{Gel Preparation}

A standard gel formulation as base of the preparations was used in this study. Gel containing $1 \%$ chlorhexidine gluconate and $1 \%$ metronidazole were prepared with the base hydroxyethyl cellulose $(1-2 \%)$, preservatives and purified water. Four series of gel were made. This included gel containing 1\% CHX gluconate, gel containing 1\% MTZ, gel of CHX and MTZ as a combined preparation and gel without drug as placebo. All preparations were made in the laboratory of a pharmaceutical company and packed in plastic tubes which were separately encoded as A,B,C and D.

\section{Participant Selection and Screening}

One hundred and fifty participants were assessed for eligibility. Among them 136 participants satisfying the inclusion criteria and willing to undergo the treatment were selected for the study. For inclusion, participants had to be systemically healthy with following characteristics.(1) Patients aged 30-60 years (either of the genders), (2) periodontitis with minimum of 22 teeth present,(3) Probing depth of 4-6 $\mathrm{mm}$ in at least 2 teeth per quadrant, (4) Non-smoker. Participants were excluded if the initial interview revealed (1) Any systemic condition that could affect the progression of periodontal disease or would require prophylactic antibiotic, (2) Known allergy to metronidazole and chlorhexidine, (3) Pregnancy and lactating women, (4) Grade II and III mobility, (5) Any teeth with furcation involvement, (6) History of periodontal therapy 6 months back, (7) Use of systemic or topical antimicrobial within 6 months prior to the study. The study was started in February 2014 and completed in September 2015.

\section{Randomisation and Blinding}

Patients were randomly divided into 4 groups. Randomisation was done by simple lottery method for which different chits were prepared with A, B, $\mathrm{C}$ and $\mathrm{D}$ written on them and kept in a box. For every patient a chit was selected randomly and accordingly the patient was assigned with the group written on that chit as A,B,C and D where, Group A received SRP with topical gel application coded as 'A', Group B received SRP with topical gel application coded as 'B', Group C received SRP with topical gel application coded as ' $\mathrm{C}$ ' and Group $\mathrm{D}$ received SRP with topical gel application coded as ' $\mathrm{D}$ '. The operator and the patient both were blinded. Therefore the tubes were coded as A, B,C and D. After the completion of the clinical procedure and subsequent follow up drugs were decoded during statistical analysis. 


\section{Clinical Procedure}

After the recruitment of eligible participants, impressions were taken for fabrication of acrylic stents. Customized acrylic occlusal stent with vertical grooves were prepared for each subject on a study model to standardize the readings and to ensure the reproducibility of measurements during the subsequent examinations.

At the baseline visit, all the clinical parameters were recorded which included: Plaque Index (Silness and Loe, 1964); Gingival Index (Loe and Silness, 1963); Probing Pocket Depth and Clinical Attachment Level. After recording the parameters, full mouth scaling with ultrasonic piezoelectric scaler and root planing with hufreidy gracey curettes was performed. The sites were irrigated gently with normal saline and left for 10 minutes to achieve haemostasis prior to placement of the respective drug. A $3 \mathrm{ml}$ disposable syringe was taken and the tip of the cannula was made blunt so as to prevent tissue injury that may be caused by the sharp needle tip. The syringe was then loaded with the respective drug group for the local drug delivery. Isolation and drying followed by drug delivery subgingivally to the base of periodontal pocket was done. The confirmation of sufficient amount of drug deposition in the pocket was gained by gel seen at the gingival margin of the respective tooth being treated. Then periodontal dressing was placed. Postoperative home care instructions including brushing with a soft brush twice a day was advised and use of chemotherapeutics and

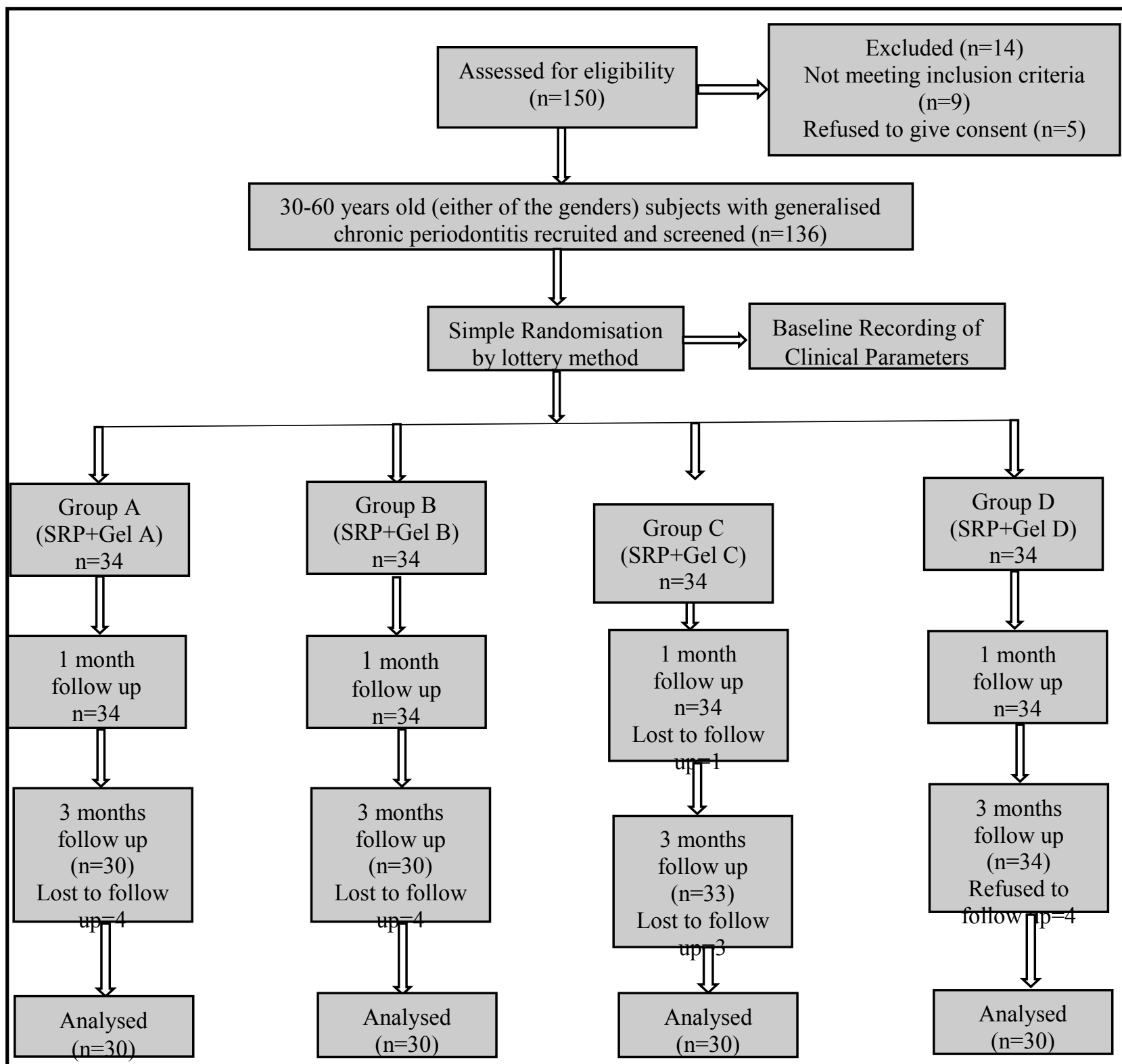

Figure 1. Flowchart of the study protocol showing the enrolment of subjects followed by randomization and review upto 3 months post therapy. 
irrigation devices were not recommended.

Patients were recalled after 1 week for removal of the periodontal dressing and for reinforcement of oral hygiene maintenance. Recall visits were scheduled after 1 month and 3 months for recording the clinical parameters.

\section{Data Analysis}

The mean and standard deviation was calculated for all the clinical parameters of the control group and test groups. Inter-group comparison for clinical parameters was done using analysis of variance (ANOVA) post hoc tukey test. Intra-group comparison for the change in clinical parameters during different time intervals was done for each group using paired t-test. The P-value $<0.05$ was considered significant. All the analysis were carried out by using SPSS version 20 .

\section{RESULTS}

In this study, a total of 150 subjects were assessed for eligibility out of which 14 (nine did not meet the inclusion criteria and five refused to give consent) were excluded. Thus, 136 subjectswere enrolled. At the end of the study, total of 12 patients lost to follow up and four refused to follow up. Therefore, complete records of the clinical parameters from baseline to 3 months follow up were available for 120 patients which comprised of 49 females $(40.8 \%)$ and 71 males $(50.2 \%)$. Table 1 and Figure 2 shows a significant reduction in the mean plaque index score in all the groups but the mean difference of reduction from baseline to 3 months was maximum in the CHX group.
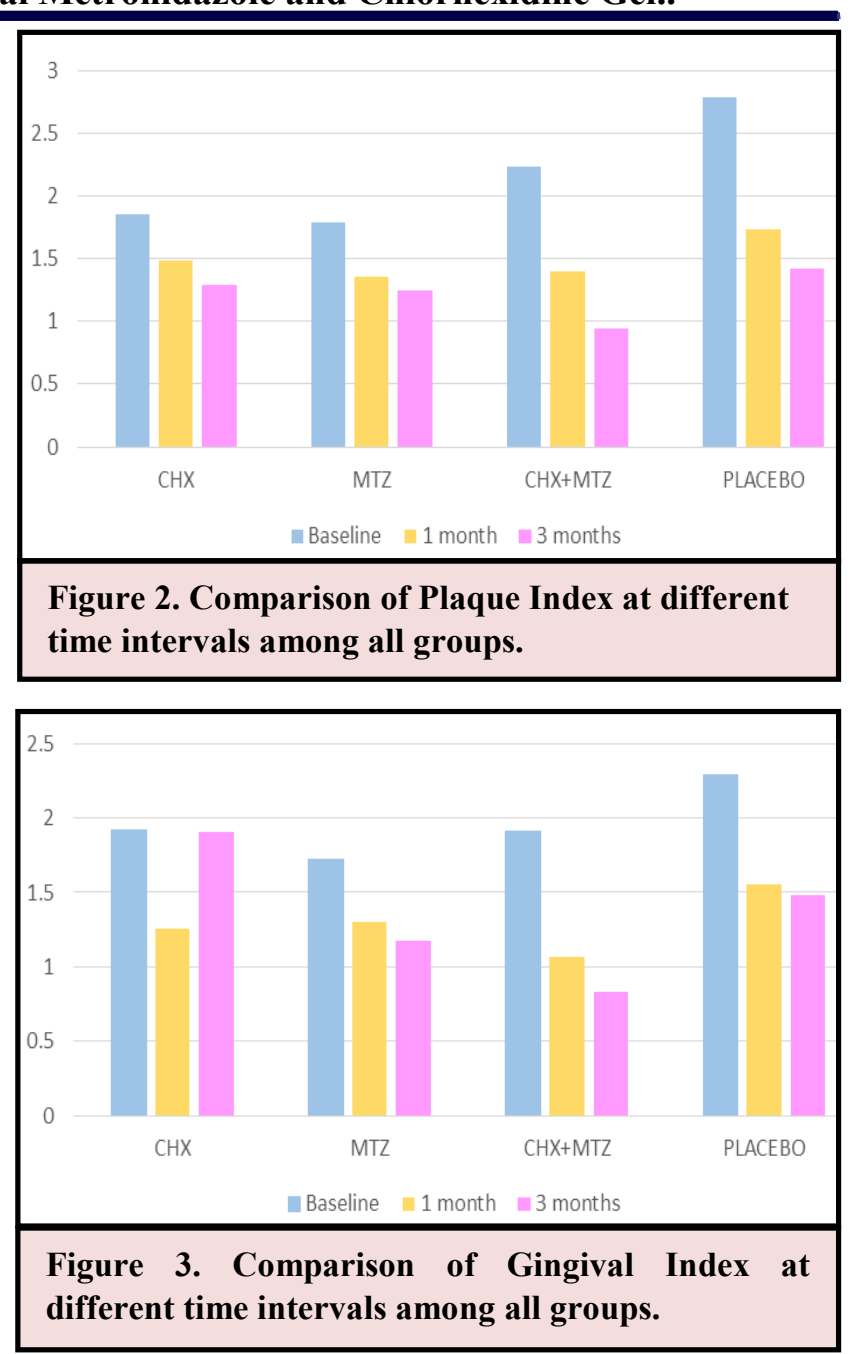

Table 2 and Figure 3 shows the significant reduction in the mean gingival index score in all the groups but the maximum change in mean gingival index score from baseline to 3 months was seen in

\begin{tabular}{|lccccc|}
\hline \multicolumn{5}{|c|}{ Table 1. Comparison of Plaque Index at different time intervals between all groups. } \\
\hline & $\mathbf{C H X}$ & $\mathbf{M T Z}$ & $\mathbf{C H X}+\mathbf{M T Z}$ & PLACEBO & Tukey test significance of P \\
Mean \pm SD & Mean \pm SD & Mean \pm SD & Mean \pm SD & \\
Baseline & $1.85 \pm 0.43$ & $1.79 \pm 0.39$ & $2.23 \pm 0.43$ & $2.79 \pm 0.56$ & $0.974^{\mathrm{a}}, 0.006^{\mathrm{b}}, 0.00^{\mathrm{c}}, 0.00^{\mathrm{d}}, 0.000^{\mathrm{e}}, 0.000^{\mathrm{f}}$ \\
1 month & $1.49 \pm 0.23$ & $1.36 \pm 0.30$ & $1.40 \pm 0.43$ & $1.74 \pm 0.31$ & $0.437^{\mathrm{a}}, 0.805^{\mathrm{b}}, 0.017^{\mathrm{c}}, 0.930^{\mathrm{d}}, 0.000^{\mathrm{e}}, 0.001^{\mathrm{f}}$ \\
3 months & $1.29 \pm 0.25$ & $1.25 \pm 0.33$ & $0.94 \pm 0.31$ & $1.42 \pm 0.49$ & $0.982^{\mathrm{a}}, 0.002^{\mathrm{b}}, 0.420^{\mathrm{c}}, 0.006^{\mathrm{d}}, 0.229^{\mathrm{e}}, 0.000^{\mathrm{f}}$ \\
\hline P-value & $0.001^{*}, 0.001^{* *}$, & $0.001^{*}, 0.001^{* *}$, & $0.001^{*}, 0.001^{* *}$, & $0.001^{*}, 0.001^{* *}$, & \\
& $0.001^{* * *}$ & $0.008^{* * *}$ & $0.000^{* * *}$ & $0.000^{* * *}$ & \\
\hline
\end{tabular}

${ }^{a}$ comparison between $C H X$ and $M T Z,{ }^{b}$ comparison between $C H X$ and $C H X+M T Z,{ }^{c}$ comparison between CHX and Placebo, ${ }^{d}$ comparison between MTZ and CHX+MTZ, ${ }^{e}$ comparison between MTZ and Placebo, ${ }^{f}$ comparison between CHX+MTZ and Placebo, * comparison between baseline and 1 month, ${ }^{* *}$ comparison between baseline and 3 months, ${ }^{* * *}$ comparison between 1 month and 3 months.

\begin{tabular}{|c|c|c|c|c|c|}
\hline & $\begin{array}{c}\text { CHX } \\
\text { Mean } \pm \text { SD }\end{array}$ & $\begin{array}{c}\text { MTZ } \\
\text { Mean } \pm \text { SD }\end{array}$ & $\begin{array}{l}\text { CHX+MTZ } \\
\text { Mean } \pm \text { SD }\end{array}$ & $\begin{array}{l}\text { PLACEBO } \\
\text { Mean } \pm \text { SD }\end{array}$ & $\begin{array}{c}\text { Tukey test sig. } \\
\text { of } P\end{array}$ \\
\hline Baseline & $1.92 \pm 0.30$ & $1.72 \pm 0.28$ & $1.91 \pm 0.42$ & $2.29 \pm 0.37$ & $0.129^{\mathrm{a}}, 1.000^{\mathrm{b}}, 0.000^{\mathrm{c}}, 0.156^{\mathrm{d}}, 0.000^{\mathrm{e}}, 0.000^{\mathrm{f}}$ \\
\hline 1 month & $1.26 \pm 0.29$ & $1.30 \pm 0.22$ & $1.07 \pm 0.37$ & $1.55 \pm 0.39$ & $0.941^{\mathrm{a}}, 1.49^{\mathrm{b}}, 0.004^{\mathrm{c}}, 0.039^{\mathrm{d}}, 0.025^{\mathrm{e}}, 0.000^{\mathrm{f}}$ \\
\hline 3 months & $1.91 \pm 0.42$ & $1.17 \pm 0.19$ & $0.83 \pm 0.26$ & $1.48 \pm 0.44$ & $0.999^{\mathrm{a}}, 0.000^{\mathrm{b}}, 0.002^{\mathrm{c}}, 0.000^{\mathrm{d}}, 0.001^{\mathrm{e}}, 0.000^{\mathrm{f}}$ \\
\hline P-Value & $\begin{array}{l}0.000^{*}, 0.000^{* *}, \\
0.004 * * *\end{array}$ & $\begin{array}{l}0.000^{*}, 0.000^{* *}, \\
0.000^{* * *}\end{array}$ & $\begin{array}{l}0.000^{*}, 0.000^{* *} \\
0.000^{* * *}\end{array}$ & \multicolumn{2}{|l|}{$\begin{array}{l}0.000^{*}, 0.000 * * \\
0.083^{* * *}\end{array}$} \\
\hline $\begin{array}{l}{ }^{a} \text { comparison } \\
\text { MTZ and } C H \\
\text { month, }{ }^{* *} \text { con }\end{array}$ & eeen $C H X$ and $N$ & $\overline{{ }^{b}{ }^{b} \text { comparison } b}$ & ween $\mathrm{CHX}$ and $\mathrm{C}$ & $+M T Z,{ }^{c}$ compari & $\begin{array}{l}\text { in between CHX and Placebo, }{ }^{d} \text { comparison be } \\
Z \text { and Placebo, *comparison between baseline } \\
\text { onths. }\end{array}$ \\
\hline
\end{tabular}


the $\mathrm{CHX}+\mathrm{MTZ}$ group.

Table 3 and Figure 4 shows significant reduction in probing pocket depth in all the groups from baseline to 3 months but again the $\mathrm{CHX}+\mathrm{MTZ}$ group showed the maximum reduction in mean probing pocket depth from baseline to 3 months.

\begin{tabular}{|c|c|c|c|c|c|}
\hline & $\begin{array}{c}\text { CHX } \\
\text { Mean } \pm \text { SD }\end{array}$ & $\begin{array}{c}\text { MTZ } \\
\text { Mean } \pm \text { SD }\end{array}$ & $\begin{array}{l}\text { CHX + MTZ } \\
\text { Mean } \pm \text { SD }\end{array}$ & $\begin{array}{l}\text { PLACEBO } \\
\text { Mean } \pm \text { SD }\end{array}$ & $\begin{array}{c}\text { Tukey test sig } \\
\text { of } P\end{array}$ \\
\hline Baseline & $5.22 \pm 0.47$ & $5.30 \pm 0.58$ & $5.47 \pm 0.58$ & $5.33 \pm 0.24$ & $0.899^{\mathrm{a}}, 0.197^{\mathrm{b}}, 0.773^{\mathrm{c}}, 0.565^{\mathrm{d}}, 0.994^{\mathrm{e}}, 0.728^{\mathrm{f}}$ \\
\hline 1 month & $3.95 \pm 1.12$ & $4.55 \pm 0.62$ & $4.58 \pm 0.65$ & $4.83 \pm 0.75$ & $0.25^{\mathrm{a}}, 0.16^{\mathrm{b}}, 0.000^{\mathrm{c}}, 0.99^{\mathrm{d}}, 0.510^{\mathrm{e}}, 0.606^{\mathrm{f}}$ \\
\hline 3 months & $3.63 \pm 0.85$ & $4.16 \pm 0.61$ & $3.85 \pm 0.56$ & $4.59 \pm 0.81$ & $0.025^{\mathrm{a}}, 0.645^{\mathrm{b}}, 0.000^{\mathrm{c}}, 0.334^{\mathrm{d}}, 0.102^{\mathrm{e}}, 0.001$ \\
\hline P-Value & $\begin{array}{c}0.000^{*}, 0.000^{* *}, \\
0.000^{* * * *}\end{array}$ & $\begin{array}{c}0.000^{*}, 0.000^{* *}, \\
0.000^{* * *}\end{array}$ & $\begin{array}{c}0.000^{*}, 0.000^{* *}, \\
0.000^{* * *}\end{array}$ & $\begin{array}{c}0.00 I^{*}, 0.000^{* *}, \\
0.000^{* * *}\end{array}$ & \\
\hline
\end{tabular}

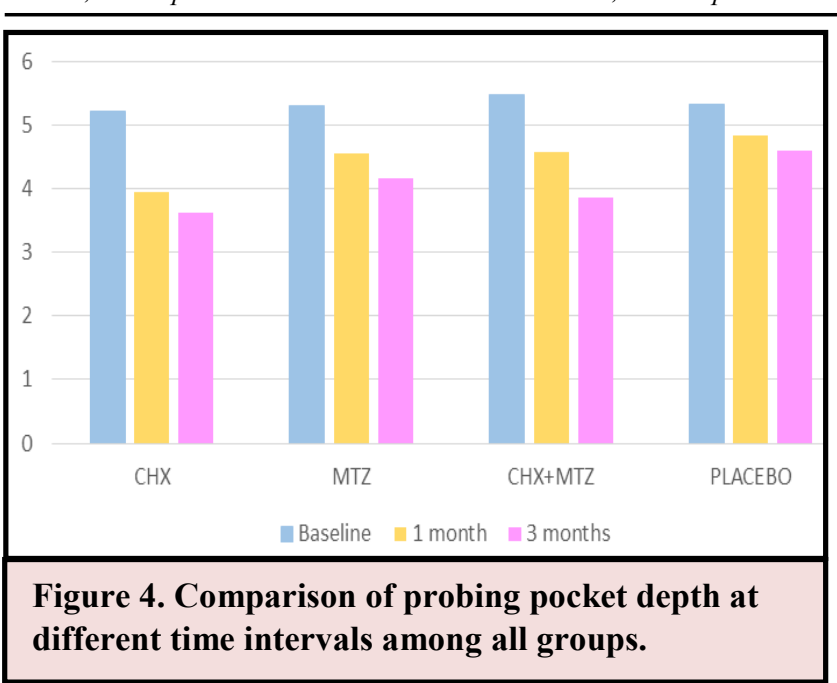

Statistically significant gain in clinical attachment level in all the groups was appreciated when compared at different time intervals. As in most of the parameters, $\mathrm{CHX}+\mathrm{MTZ}$ group again showed the maximum gain from baseline to 3 months (Table 4 and Figure 5).

\section{DISCUSSION}

In the present study, an attempt was made to evaluate the efficacy of CHX and MTZ gel alone or in combination, as an adjunct to SRP in the treatment of chronic periodontitis. These antimicrobials were chosen because of their proven efficacy in the management of periodontal diseases. The form of drug used in the study

Table 4. Comparison of Clinical Attachment Level among all groups at different time intervals.

\begin{tabular}{|c|c|c|c|c|c|}
\hline & $\begin{array}{c}\text { CHX } \\
\text { Mean } \pm \text { SD }\end{array}$ & $\begin{array}{c}\text { MTZ } \\
\text { Mean } \pm \text { SD }\end{array}$ & $\begin{array}{l}\text { CHX+MTZ } \\
\text { Mean } \pm \text { SD }\end{array}$ & $\begin{array}{l}\text { PLACEBO } \\
\text { Mean } \pm \text { SD }\end{array}$ & $\begin{array}{c}\text { Tukey test sig } \\
\text { of } P\end{array}$ \\
\hline Baseline & $3.96 \pm 1.21$ & $4.29 \pm 1.09$ & $4.94 \pm 1.17$ & $4.88 \pm 1.03$ & $0.674^{\mathrm{a}}, 0.006^{\mathrm{b}}, 0.10^{\mathrm{c}}, 0.117^{\mathrm{d}}, 0.178^{\mathrm{e}}, 0.997^{\mathrm{f}}$ \\
\hline 1 month & $3.74 \pm 1.26$ & $4.04 \pm 1.06$ & $4.49 \pm 1.02$ & $4.76 \pm 1.06$ & $0.705^{\mathrm{a}}, 0.049^{\mathrm{b}}, 0.003^{\mathrm{c}}, 0.420^{\mathrm{d}}, 0.065^{\mathrm{e}}, 0.771^{\mathrm{f}}$ \\
\hline 3 months & $3.55 \pm 1.26$ & $3.78 \pm 1.09$ & $4.25 \pm 0.99$ & $4.58 \pm 1.08$ & $0.839^{\mathrm{a}}, 0.073^{\mathrm{b}}, 0.003^{\mathrm{c}}, 0.370^{\mathrm{d}}, 0.032^{\mathrm{e}}, 0.654^{\mathrm{f}}$ \\
\hline P-value & $\begin{array}{c}0.001^{*}, 0.000^{* *} \\
0.000^{* * *}\end{array}$ & $\begin{array}{c}0.001^{*}, 0.000^{* *} \\
0.000^{* * *}\end{array}$ & $\begin{array}{c}0.001^{*}, 0.000^{* *} \\
0.000^{* * *}\end{array}$ & $\begin{array}{c}0.001^{*}, 0.000^{* *} \\
0.000^{* * *}\end{array}$ & \\
\hline
\end{tabular}

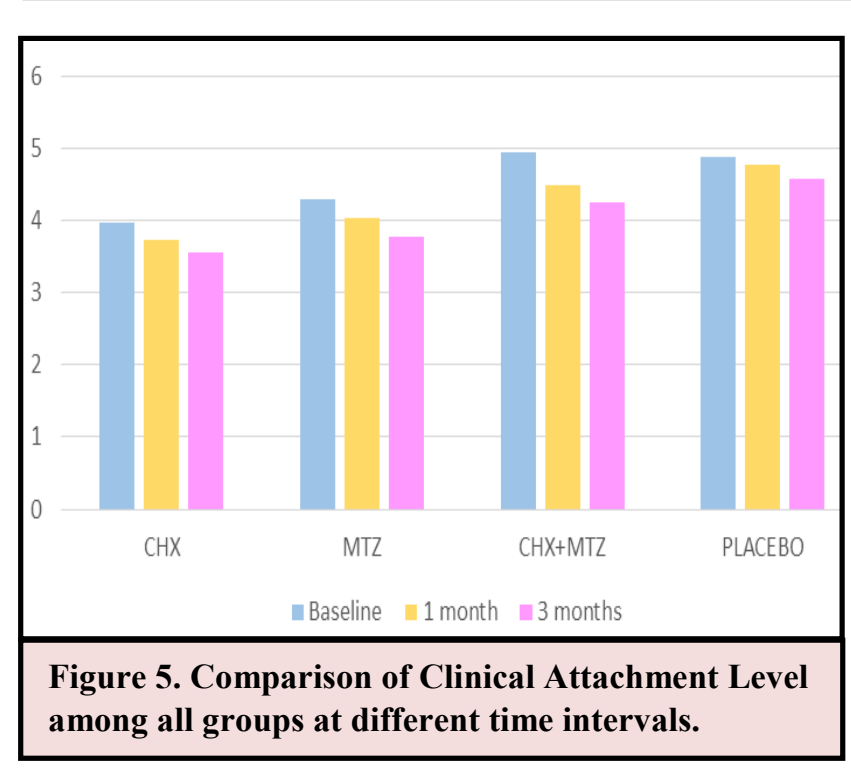

is gel which has an advantage over other forms like mouth rinse, irrigation etc. For a semi-solid formulation like gel to retain in the pocket, it should undergo a change into a sticky semi-solid or solid phase so that it will prevent the drug from being flushed out of the pocket by the GCF flow. ${ }^{14}$ In addition, to be successful in the treatment of periodontitis, local delivery regimens must provide therapeutic levels of the antimicrobial agent in the subgingival area over a prolonged period of time. In relation to this, minimum inhibitory concentration (MIC) is determined by the concentration required to inhibit the growth of $90 \%$ of strains. The MIC for susceptible anaerobic bacteria generally ranges from 0.1 to $8 \mathrm{mg} / \mathrm{ml}$. The MIC of metronidazole required (MIC50) to affect strains relevant to periodontal pathology is $<1 \mathrm{mg} / \mathrm{ml}^{15}$ and $0.10 \mu \mathrm{g} / \mathrm{ml}$ for Chlorhexidine. ${ }^{16}$ 
The CHX and MTZ gel used in the study is composed of $1-2 \%$ Hydroxyethyl cellulose as base. The gels composed of hydroxyethyl cellulose lack sustained release property. However, the property of bioadhesion or mucoadhesion is exhibited which is the crucial requirement for prolonged drug release at the site. ${ }^{14}$ As a result, beneficial clinical results have been reported in cases of periodontitis through application of such gels.

In the present study, there was a statistically significant reduction in mean plaque index score, mean gingival index score, periodontal probing depth and clinical attachment loss in all four groups when observed in 1 and 3 months follow up. A significant reduction in mean plaque index score was observed in all groups but the mean difference of reduction from baseline to 3 months was maximum in the CHX group. This result could be attributed to the antiplaque effect of $\mathrm{CHX}$ which is similar to the effect reported in a study where subgingival irrigation with $\mathrm{CHX}$ rinse demonstrated a significant reduction in formation of supragingival plaque, associated erythema and bleeding on probing when compared to control. ${ }^{17}$ These results are in accordance with other studies that have proved the efficacy of $\mathrm{CHX}$ alone in inhibiting the formation of supragingival plaque. $\mathrm{CHX}$ has been used as an effective antiseptic agent for more than 30 years in the management of periodontal diseases. It exhibits a broad spectrum of topical antimicrobial activity, safety, effectiveness, and property of substantivity. ${ }^{18}$

On the other hand, the maximum change in mean gingival index score from baseline to 3 months was observed in $\mathrm{CHX}+\mathrm{MTZ}$ group. This maximum change could be attributed to the synergistic effect shown by the presence of both CHX and MTZ in the combination group. Several combined therapies for the treatment of periodontal infections have been shown to be successful by Greenstein, Grisi et al, Levy et al and Lindheet al. ${ }^{19-22}$ Other drug groups i.e. CHX, MTZ and Placebo also showed a significant reduction in mean gingival index score. But this finding is in contrast to the study done by Perinettiet $\mathrm{al}^{23}$ where local application of $1 \% \mathrm{CHX}, 1 \%$ MTZ and Placebo after scaling and root planing in three different groups did not change the mean gingival index score to a statistically significant level.

Periodontal pocket formation is pathognomonic for periodontitis, hence pocket probing is crucial in the diagnosis of periodontitis and evaluating the success of periodontal therapy. In the present study, the maximum reduction in probing pocket depth 3 months was shown by $\mathrm{CHX}+\mathrm{MTZ}$ group. This reduction is attributed to the antimicrobial effects of both locally delivered drugs and is in accordance with study done by Jenabianet $\mathrm{al}^{24}$ where the use of tooth paste as a mode of drug delivery has been made rather than gel. In the 3 months follow up, CHX, MTZ as well as Placebo showed significant reduction in the mean probing depth. Similar results have been shown by Salvi et al, where comparison among three drug groups namely Atridox, Elyzol Dental gel and
Periochip have been made. ${ }^{25}$

The CAL measurements at 1 month recall showed to follow a trend similar to probing pocket depth, however, they could not reach levels that could be considered clinically significant. The CAL changes were shown to be statistically significant in all groups when compared at different time intervals. As in most of the parameters, $\mathrm{CHX}+\mathrm{MTZ}$ group showed the maximum gain in clinical attachment level too. Similarly, $\mathrm{CHX}$ group was also shown to be effective which is in agreement with the studies done by Soskolneet al, ${ }^{26}$ Jeffcoat et al, ${ }^{27}$ where CHX chip was used as an adjunct to SRP. On the contrary, the study results of Grisiet $\mathrm{al}^{20}$ does not support this finding as per the gain in clinical attachment level.

The clinical parameters were recorded at baseline, 1 month and 3 months follow up. The first follow up was planned for 1 month because of the fact that substantial pocket depth reduction can take place in within 4 weeks of a single episode of root planing in association with improved oral hygiene measures to maintain low levels of supragingival plaque as concluded by Proye et $\mathrm{al}^{28}$. The 3 months follow up was scheduled on the basis of the conclusion made by Caton et $\mathrm{al}^{29}$ according to which favorable clinical changes appreciated in periodontal pockets within 1 month after a single intervention through root planing in association with improved oral hygiene can be maintained for an additional 3 month time period. During the study period none of the subjects reported any oral symptoms or other adverse effects.

The maximum change in healing that could be appreciated clinicallyhas been noted to occur during the measurement done from baseline to 1 month. This has been explained by Cercek and coworkers ${ }^{30}$ who noted clinical improvements to continue for 8 months, however, most of the healing occurred during the first month. It appears that, the maximum change in relation to probing depth reduction and clinical attachment gain can be appreciated after 4 to 6 weeks, nevertheless, subsequent repair and maturation of the periodontium may occur over 9 to 12 months.

Hence, in the present study all the groups showed a significant change in the clinical parameters during different time intervals. The inter-group comparison of the antimicrobials showed the CHX+MTZ to be the most efficacious group in the treatment of chronic periodontitis both in 1 month and 3 months. This can be attributed to the combined property of substantivity possessed by $\mathrm{CHX}$ along with bactericidal potential of MTZ.

However, some limitations have been taken into account in the study. The inclusion of microbiological and biochemical aspects along with the clinical parameters could have given more meaning to our results. Further, studies with larger sample size and use of advanced diagnostic aids probably with a split mouth study design might lead to successful treatment of chronic periodontitis. 


\section{CONCLUSIONS}

From this study, we can conclude that local drug delivery of CHX, MTZ used alone or combined shows significant clinical advantage as an adjunct to scaling and root planing in the non-surgical management of chronic periodontitis. The use of $\mathrm{CHX}+\mathrm{MTZ}$ with SRP appears to be superior as evidenced by reduction in all the clinical parameters.

\section{ACKNOWLEDGEMENTS}

I gratefully acknowledge Universal College of Medical Sciences, college of dental surgery, Bhairahawa, Nepal where the study was conducted and the team of Asian Pharmaceutical Private Limited, Bhairahawa for preparation and coding of the drugs used in the study.

\section{REFERENCES}

1. Ryan ME. Nonsurgical approaches for treatment of periodontal diseases. Dent Clin N Am. 2005;49:611-636.

2. Goodson JM, Hogan PE, Dunham SL. Clinical responses following periodontal treatment by local drug delivery. J Periodontol 1985; 56:8187.

3. Dodwad V, Vaish S, Mahajan A, Chhokra M. Local drug delivery in periodontics: a strategic intervention. Int J Pharm Sci 2012; 4: 30-34.

4. Jones CG. Chlorhexidine:is it gold standard? Periodontology 2000 1997;15: 52-62.

5. Soskolne A, Golomb G, Friedman M and Sela MN. New sustained release dosage form of chlorhexidine for dental use. II. Use in periodontal therapy. J Periodontal Res 1983;18 (3):330-336.

6. Divya PV, K Nandakumar. Local drug deliveryPeriodol in periodontics. Tren Bio Art Org. 2006; 19:78-80.

7. Cosar C, Julou L. Activity of 1-(2hydroxyethyl)-2-methyl-5-nitroimidazole (8823 RP) against experimental Trichomonas vaginalis infection. Ann. Inst. Pasteur 1959 96:238-241.

8. Shinn DLS. Metronidazole in acute ulcerative gingivitis. Lancet 1962;279:1191-0.

9. Clay BW, Katherine K, Baehni P. Chemotherapeutics: antibiotics and other antimicrobials. Periodontol 2000 2004; 36: 146165.

10. Pedrazzoli V, Kilian M, Karring $T$. Comparative clinical and microbiological effects of topical subgingival application of metronidazole $25 \%$ dental gel and scaling in the treatment of adult periodontitis. J Clin Periodontol 1992; 19: 715-722.

11. Griffiths GS, Smart GJ, Bulman JS et al. Comparison of clinical outcomes following treatment of chronic adult periodontitis. J Clin Periodontol 2000; 910-917.

12. Perinetti G, Paolantonio M, Cordella $\mathrm{C}$ et al. Clinical and microbiological effects of subgingival administration of two active gels on

persistent pockets of chronic periodontitis patients. J Clin Periodontol 2004;31: 273-281.

13. Rudhart A, Purucker P, Kage A, Hopfenmüller W, Bernimoulin JP. Local Metronidazole Application in Maintenance Patients. Clinical and Microbiological Evaluation. J Periodontol.1998; 69(10):1148-1154.

14. Rajesh H, Boloor VA, Rao AS, Prathap S, Haziel JD. Localy drug delivery devices used for treating periodontitis-a review. J Glob Biosc 2014;3(6): 904-909.

15. Baker PJ, Evans RT, Slots J, Genco RJ. Antibiotic susceptibility of anaerobic bacteria from the human oral cavity. J Dent Res 1985;64 (10):1233-1244.

16. Verma A, Sanghi S, Grover D, Aggarwal S, Gupta R, Pandit N. Effect of insertion of xanthan-based chlorhexidine gel in the maintenance phase following the treatment of chronic periodontitis. J Indian Soc Periodontol. 2012;16(3):381-385.

17. Fine JB, Harper DS, Gordon JM, Hovliaras CA, Charles $\mathrm{CH}$. Short term microbiological and clinical effects of subgingival irrigation with an antimicrobial mouthrinse. J Periodontol 1994;65(1):30-36.

18. Loe H, Schiott, CR. The effect of mouthrinses and topical application of chlorhexidine on the development of dental plaque and gingivitis in man. J Periodontal Res 1970;5(2):79-83.

19. Greenstein G. Periodontal response to mechanical non-surgical therapy: a review. J Periodontol 1992;63(2):118-130.

20. Grisi DC, Salvador SL, Figueiredo LC, Souza SL, Novaes AB, Grisi MF. Effect of a controlled-release chlorhexidine chip on clinical and microbiological parameters of periodontal syndrome. J Clin Periodontol. 2002;29(10):87581.

21. Levy RM, Giannobile WV, Feres M, Haffajee AD, Claire S, Socransky SS.The effect of apically repositioned flap surgery on clinical parameters and the composition of the subgingival microbiota: 12-month data. Int $\mathrm{J}$ Periodontics Restorative Dent 2002;22(3):209- 
219.

22. Lindhe J, Liljenberg B, Adielsson B. Effect of long-term tetracycline therapy on human periodontal disease. J Clin Periodontol 1983;10 (6):590-601.

23. Perinetti G, Paolantonio M, Cordella C, D'Ercole S, Serra E, Piccolomini R. Clinical and microbiological effects of subgingival administration of two active gels persistent pockets of chronic periodontitis patients.J Clin Periodontol 2004; 31(4):273-281.

24. Jenabian N, Abedi, Tayebi P, Moghadamnia AA. Local Delivery of Metronidazole and Chlorhexidine as Toothpaste in treatment of Adult Periodontitis.International Journal of Pharmacology 4(5): 361-368, 2008.

25. Salvi GE, Mombelli A, Mayfield L, Rutar A, Suvan J, Garrett S et al.Local antimicrobial therapy after initial periodontal treatment. J Clin Periodontol 2002;29(6):540-50.

26. Soskolne WA, Heasman PA, Stabholz, A, Smart GJ, Palmer M, Flashner $M$ et al. Sustained local delivery of chlorhexidine in the treatment of periodontitis:A multi-center study. J Periodontol 1997;68(1):32-38.

27. Jeffcoat MK, Bray KS, Ciancio SG, Dentino AR, Fine DH, Gordon JM et al. Adjunctive use of a subgingival controlled-release chlorhexidine chip reduces probing depth and improves attachment level compared with scaling and root planing alone. J Periodontol 1998; 69(9):989-997.

28. Proye M, Caton J, Poison A. Initial Healing of Periodontal Pockets After a Single Episode of Root Planing Monitored by Controlled Probing Forces. J. Periodontol.1982; 53(5):296-301.

29. Caton J, Proye M, and Polson A. Maintenance of healed periodontal pockets after a single episode of root planing. J Periodontol 1982;53 (7):420-424.

30. Cercek JF, Kiger RD, Garrett S, Egelberg J. Relative effects of plaque control and instrumentation on the clinical parameters of human periodontal disease. J Clin Periodontol 1983;10(1):46-56.

Citation: Acharya P, Kumar M, Saimbi CS. Clinical Evaluation of Topical Metronidazole and Chlorhexidine Gel following Scaling and Root Planing in Patients with Chronic Periodontitis. JCMS Nepal. 2019;15(1):10-7. 